\title{
Uma Estranha Diáspora Rumo a Portugal: Judeus e Cristãos-Novos Reduzidos à Fé Católica no século XVII
}

\author{
Isabel M. R. Mendes Drumond BRAGA \\ Universidade de Lisboa
}

1. D. Manuel assinou, em Muge, a 5 de Dezembro de 1496, uma «carta patente» em que mandou que todos os judeus e mouros saíssem de Portugal até 31 de Outubro de $1497^{1}$. Como se temessem ataques contra os judeus, o rei colocou-os, nesse mesmo dia, sob a sua protecção, para que ficassem «mais seguros, honrados, bem tratados, assim de feito como de palavra do que até aqui eram» ${ }^{2}$. Não restam hoje dúvidas de que D. Manuel I não pretendia a saída, na totalidade, dos judeus de Portugal. Se o documento de 1496 dava a liberdade de êxodo aos filhos de Israel, logo se colocaram entraves ao mesmo. Começou por se limitar os barcos em que podiam partir, para depois se restringirem os portos de embarque, para além de se passar a exigir a permissão real para a saída. De três portos determinados funcionou apenas um, o de Lisboa. Para reforçar a conversão, tiraram-lhes os filhos, que foram

${ }^{1}$ Ordenações Manuelinas, reprodução fac-simile da edição de 1797 (Lisboa: Fundação Calouste Gulbenkian 1984) livro II, tít. 41, pp. 212-214. Sobre esta questão cf. João José Alves DiAs, Isabel M. R. Mendes Drumond BraGA e Paulo Drumond BRAGA, «A Conjuntura», em Portugal do Renascimento à Crise Dinástica, Nova História de Portugal, vol. 5, eds. Joel Serrẽo e A. H. de Oliveira MARQUES (Lisboa 1998) pp. 721-724.

${ }^{2}$ Lúcia Liba MuCZnik (ed.), Os Judeus Portugueses e a Expulsão. Catálogo da Exposição evocativa dos 500 anos da Expulsão dos Judeus de Portugal (Lisboa 1996) p. 25.

Sefarad 62 (2002) págs. 259-274

(c) CSIC

ISSN 037-0894 
baptizados à força. Seguiu-se o baptismo forçado dos adultos. Tentava-se, por tudo, a conversão, em vez da saída. D. Manuel chegou a publicar, em Maio de 1497, uma lei em que se comprometia a não deixar inquirir sobre os comportamentos religiosos no espaço de vinte anos, lei essa que voltou a ser renovada em 1512, por mais 16 anos. Aos poucos eram-lhes tomadas as sinagogas, embora a prática da religião judaica ainda fosse legal, mas caminhando já para a clandestinidade ${ }^{3}$.

Uma minoria optou pela saída do reino ao longo dos séculos xVi e xvir. Os destinos preferidos foram o Norte de África ${ }^{4}, \mathrm{o}$ Oriente, onde se espalharam sobretudo por Goa, Cochim e Ormuz, mas também, em menor número, por Cambaia, Baçaim, Chaul, Cabo Comorim, São Tomé, Bengala, Pegu, Tanassarim, Malaca, Sião, Maluco, Japão, China e diversas terras do Malabar, para além de terem a possibilidade de passarem para zonas fora do controle português ${ }^{5}$; e várias zonas da Europa, espe-

${ }^{3}$ Maria José Pimenta Ferro Tavares, Os Judeus em Portugal no Século XV, vol. 1, (Lisboa 1982) pp. 484-500.

${ }^{4}$ Jacques BERQUE, «Des 'Marranos' Musulmans à Fez?», em Mélanges en Honneur de Fernand Braudel, vol. 1 (Histoire Économique du Monde Méditerranéen 1450-1650) (Paris 1973) pp. 123-135; Elias LIPINER, «Os Conversos refugiados na África Quinhentista. Descrição por um Autor Português Coevo», em Os Baptizados em Pé. Estudos acerca da Origem e da Luta dos Cristãos-Novos em Portugal (Lisboa 1998) pp. 297-315; Idem, «A Ponte sobre o Estreito. Diligência, no Ano de 1627, sobre a Vida dos Judeus de Ceuta», Ibidem, pp. 317-328; José Alberto Rodrigues da Silva TAVIM, Os Judeus na Expansão Portuguesa em Marrocos durante o Século XVI. Origens e Actividade duma Comunidade (Braga 1997). Sobre as fugas dos judeus e cristãos-novos de origem castelhana, cf. Enrique CANTERA MonTEnegro, «El Asentamiento de Judíos Castellanos en el Norte de África tras la Expulsión de 1492: Causas y Consecuencias», em Congreso Internacional El Estrecho de Gibraltar, vol. 2 (Madrid 1988) pp. 277. 288; Yosef KAPLAN, «La Diáspora Judeo-Española-Portuguesa en el Siglo XVII: Tradición, Cambio y Modernización», Manuscrits. Revista d'Historia Moderna 10 (1992) pp. 77-89; Michel ABIтBOL, «Juifs d'Afrique du Nord et Expulsés d' Espagne après 1492», Revue de l'Histoire des Religions, 210/1 (1993) pp. 49-90.

${ }^{5}$ No caso concreto do Oriente português, sabemos que os cristãos-novos de origem castelhana ou descendentes de Castelhanos, tal como os Portugueses, o procuraram a partir da segunda década do século xvi. A intensificação do afluxo de cristãos-novos ao estado da Índia ligou-se à instabilidade e à insegurança sentida no reino desde que começou a ser posta em prática a política de integração religiosa e se estabeleceu o tribunal do Santo Ofício. No Oriente dispuseram de certa liberdade e tolerância até à devassa que os atingiu em Cochim e em Goa em 1557 e à criação do tribunal inquisitorial de Goa, em 1560. Não é por acaso que o crime de judaísmo é o mais significativo nos primeiros anos da acção do 


\section{cialmente as cidades italianas ${ }^{6}$, os Baíses Baixos ${ }^{7}$, a França ${ }^{8}$}

Santo Ofício goês (Cf. António BAIÃ̃o, A Inquisição de Goa, vol. 1 (Lisboa 1949), ao contrário do que aconteceu nos séculos XVII e XVIII (Cf. Maria de Jesus dos Martíres LOPES, «A Inquisição de Goa na Segunda Metade do século xviII. Contributo para a sua História», Studia 48 (1989) pp. 237-262; Idem, «A Inquisição de Goa na Primeira Metade de Setecentos: Uma Visita pelo seu Interior», Mare Liberum 15 (1998) pp. 107-136. Vários cristãos-novos idos para o Oriente tinham ascendência castelhana, alguns tinham mesmo nascido em Castela, outros já no Oriente (Cf. Ana Cannas da CunHA, A Inquisição no Estado da Índia. Origens (1539-1560) (Lisboa 1995); José Alberto Rodrigues da Silva TAVIM, «Os Judeus e a Expansão Portuguesa na Índia durante o século xVI. O Exemplo de Isaac do Cairo: Espião, 'Língua' e 'Judeu de Cochim de Cima'», Arquivos do Centro Cultural Calouste Gulbenkian 33 (1994) pp. 137-260). No entanto, os Portugueses ao chegarem ao Oriente encontraram também judeus castelhanos que lhe prestaram importantes serviços: cf. Maria José Pimenta Ferro TAVARES, «Judeus, Cristãos Novos e o Oriente», Estudos Orientais 3 (1992) pp. 51-61; Idem, «Judeus, Cristãos-Novos e os Descobrimentos Portugueses», Sefarad 48 (1988) p. 305; Idem, Los Judios em Portugal [tradução de Mario Merlino] (Madrid 1992) pp. 235 e 287; José Alberto Rodrigues da Silva TAviM, «A Inquisição no Oriente (século XVI e primeira metade do século XVII). Algumas Perspectivas», Mare Liberum 15 (1998) pp. 17-31.

${ }^{6}$ Sobre a Itália, cf. Yosef Haym YeRUSHALMI, From Spanish Court to Italian Ghetto. Isaac Cardoso: A Study in Seventheenth-Century Marranism and Jewish Apologetics (Londres - Nova York 1971); Jesús Antonio CID, «Judaizantes y Carreteros para un Hombre de Letras: A. Enríquez Gómez (1600-1663)», em Homenaje a Julio Caro Baroja, eds. Antonio CARreira, Jesús Antonio CiD, Manuel GutiÉrRez Esteve e Rogelio Rubio (Madrid 1978) pp. 271-300; Brian S. PUllan, "The Inquisition and the Jews of Venice: the Case of Gaspare Ribeiro, 1580-1581», Bulletin of the John Rylands University Library of Manchester $62 / 1$ (1979) pp. 207-231; Idem, The Jews of Europe and the Inquisition of Venice. 1550-1670 (Londres - Nova York 1997); Pier Cesare Ioly ZoratTINI, «The Ribeiros: a sixteenth century Family of Conversos between two Inquisitions: Lisbon and Venice», em Inquisição. Ensaios sobre Mentalidade, Heresias e Arte, ed. Anita Novinsky e Maria Luiza Tucci CARneiro (São Paulo 1992) pp. 307317; Ariel TOAFF, «Ebrei Spagnoli e Marrani nell' Itallia del Cinquecento. Caracteristiche di una Mentalitá», em Xudeus e Conversos na Historia. Actas do Congreso Internacional. Ribadavia, 14-17 de outubro de 1991, ed. Carlos BARROS (Santiago de Compostela 1994) vol. 1, pp. 195-204; Renata SEgRE, «Les Liens Économiques et Sociaux entre les Communautés Séphardes d' Italie au XVI ${ }^{\mathrm{e}}$ siècle», em 1492. L' Expulsion des Juifs d' Espagne, ed. Roland GoETSCHEL (Paris 1995) pp. 49-61.

7 Saul Levi Mortera, Tratado da Verdade da Lei de Moisés. Escrito pelo seu próprio punho em Português em Amesterdão. 1659-1660, edição fac-similada e leitura do autógrafo, com introdução e comentários de H. P. SALOMON (Coimbra 1988); David Franco MENDEs e J. Mendes dos RemÉdios, Os Judeus Portugueses em Amesterdão, edição fac-similada das edições de 1911 e 1975 , com estudo introdutório de M. Cadafaz de MATos e H. P. SALOMON (Lisboa 1990); Conde de SÃo PAYO, «Subsídios para a História dos Judeus Portugueses nos Países Baixos. O Hebreu Diogo Teixeira de Sampaio e a Carta de Brasão do Jonkeer Eduardo 
Teixeira de Matos», Arquivo Histórico de Portugal, vol. 2 (Lisboa 1936-1937) pp. 445-465; Idem, «Novos Subsídios para a História dos Judeus Portugueses nos Países Baixos», Arquivo Histórico de Portugal, vol. 3 (Lisboa 1937-1938) pp. $257-$ 262; Luís Crespo FABIÃO, «Subsídios para a História dos chamados 'Judeus Portugueses' na Indústria dos Diamantes em Amsterdão nos séculos XVII e XVIII», Revista da Faculdade de Letras, 3. ${ }^{a}$ série, 15 (1973) pp. 455-519; Maria do Rosário de Sampaio Themudo BARATA, «A Gazeta de Amsterdam de 1675 e as suas Notícias de Portugal. Um Centenário Esquecido», Arquivos do Centro Cultural Português, vol. 9 (Paris 1975) pp. 287-317; H. P. SAlomon, Os Primeiros Portugueses de Amesterdão. Documentos do Arquivo Nacional da Torre do Tombo: 1595-1600 (Braga 1983); Idem, «Myth or Anti-Myth? The Oldest Accounts concerning the Origin of Portuguese Judaism at Amsterdam», Etudes Portugaises / Portuguese Studies (Braga 1991); Benjamim N. TeEnsmA, «Os Judeus Portugueses em Amesterdão», em Flandres e Portugal na Confluência de Duas Culturas, eds. J. EverAERT e E. STOLS, (s.l.: INAPA 1991) pp. 275-287; Tirtsah Levie BERFELD, «Policy Patterns towards the Poor in the Spanish Portuguese Jewish Community of the $17^{\text {th }}$ Century Amesterdam», em $O$ Judaismo na Cultura Ocidental, (Lisboa 1993) pp. 25-32; B. N. TeEnsmA, «A História Social dos Judeus Sefarditas de Amesterdão dos séculos XVII e XVII», Ibidem, pp. 33-46; António Borges CoElHo, «Gabriel da Costa: um Exilado e Banido 'Exemplar'», em Clérigos, Mercadores, «Judeus»e Fidalgos. Questionar a História - II (Lisboa 1994) pp. 225-244; Richard AYOUN, «Jerónimo Nunes da Costa, un Diplomate et Financier entre Amsterdam et le Portugal au XVIIe siècle», em 1492. $L$ Expulsion des Juifs..., pp. 111-119; R. G. FUKS-MANSFELSD, «La Contribution des Juifs Espagnols et Portugais a la Typographie Juive d' Amsterdam», Ibidem, pp. 265-275; Jonathan I. IsRAel, La Judería Europea en la Era del Mercantilismo (1550-1750) (Madrid 1992) pp. 71-72, 85-93; Yosef KAPLAN, «La Comunidad Sefardí de Amsterdam en el siglo XVII: entre la Tradición y el Cambio», em Judios Nuevos en Amsterdam. Estudios sobre la Historia Social e Intelectual del Judaísmo Sefardí en el siglo XVII (Barcelona 1996) pp. 23-55; Idem, «La Comunidad Sefardí frente al Mundo Askenazí», Ibidem, pp. 78-106; Miriam Bodian, Hebrews of the Portuguese Nation. Conversos and Community in Early Modern Amsterdam (Bloomington 1997).

${ }^{8}$ Alfredo de CarvalHo, «Os Portugueses em Bordéus no século XVII», $O$ Instituto 90 (1936) pp. 149-171 (continuado no vol. 91, pp. 452-472 e no vol. 93 , pp. 114-185); João Simões Serra, Subsídios para a História dos Judeus Portugueses em França. A Comunidade de Baiona [Dissertação de Licenciatura em História apresentada à Faculdade de Letras da Universidade de Lisboa, exemplar mimeografado] (Lisboa 1963); Gerard NAHON, Les «Nations» Juives Portugaises du Sud-Ouest de la France (1684-1751). Documents (Paris 1981); Idem, «Le Modèle Français du Marranisme: Perspectives Nouvelles», em Inquisição: Ensaios sobre Mentalidade, Heresia e Arte..., pp. 227-265; Simon SCHWARZFuchs (ed.), Les Registres des Déliberations de la Nation Juive Portugaise de Bordeaux (17111787) (Paris 1981); Richard Ayoun, «Un Médecin Marrane au Service de la Couronne de France: Elie de Montalto», em Inquisição. Comunicações apresentadas ao $1 .^{\circ}$ Congresso Luso-Brasileiro sobre Inquisição, ed. Maria Helena Carvalho dos SANTOS (Lisboa 1989) vol. 1, pp. 73-91; Idem, "Elie de Montalto un Médecin Marrane», Inquisição: Ensaios sobre Mentalidade..., pp. 292-306; Idem, «Des Portugais à Bordeaux et à Bayonne à l'époque Moderne», Cadernos 
e vários outros destinos europeus e até americanos ${ }^{9}$. Em suma, fugas para zonas de maior liberdade e tolerância religiosas. Para os que ficaram e mantiveram secretamente o culto judaico os problemas com o Santo Ofício foram uma constante, de tal modo que o judaísmo foi o delito mais significativo durante os séculos XVI e XVII ${ }^{10}$.

2. Se são por demais conhecidos os caminhos que a comunidade judaica e cristã-nova percorreu em Portugal, como acabámos de sistematizar, também é verdade que são completamente desconhecidos os casos dos que, tendo empreendido a diáspora, acabaram por regressar, abandonando a sua fé inicial. Não nos referimos especialmente aos que, tendo partido, voltaram devido a actividades comerciais ou a uma vontade irreprimivel de doutrinar e reavivar a fé dos que tinham ficado, atitude de funestas consequências, mas aos que, aparentemente, de livre e espontânea vontade, regressaram ou se dirigiram pela primeira vez a terras de seus antepassados e se reduziram à fé católica, durante o século XVII.

Cabe em primeiro lugar perguntar porque razão uns quantos descendentes de cristãos-novos penínsulares deixaram as suas

de Estudos Sefarditas 1 (2001) pp. 9-26; Maria Ignes Correa de NovaEs, «Contribuição para a História da Família Henriques-Raba de Bordéus: Joseph Henrique Nunes, Cristão-Novo de Trás-os-Montes», Ibidem, pp. 318-323.

${ }_{9}$ Pedro de AZEvedo, «Denúncias contra os Cristãos-Novos de Londres contra o Embaixador Português naquela Corte», Boletim da Segunda Classe 9/2 (1914) pp. 461-464; Eugénio Andrea da Cunha e FreitAS, «Os Judeus Portugueses e a Aristocracia Inglesa», em Presença de Portugal no Mundo. Actas do Colóquio (Lisboa 1982) pp. 87-97; Carlos Ascenso ANDRÉ, Um Judeu no Desterro. Diogo Pires e a Memória de Portugal (Coimbra 1992); Daniel TOLleT, «Les Juifs Originaires de la Péninsule Ibérique en Europe Centrale et Orientale du XVI ${ }^{\mathrm{e}}$ au XVIII ${ }^{e}$ siècles», em 1492. L' Expulsion..., pp. 49-61; Joseph Abraham LEVI, «A Diáspora Sefardita nas Américas durante os séculos XVII e XVII», Cadernos de Estudos Sefarditas 1 (2001) pp. 27-63; Maria da Graça A. Mateus VenturA, «Os Gramaxo. Um Caso Paradigmático de Redes de Influência em Cartagena das Índias», Cadernos de Estudos Sefarditas 1 (2001) pp. 65-81.

${ }^{10}$ Sobre o crime de judaísmo, cf., especialmente, Maria José Pimenta Ferro Tavares, Los Judios en Portugal ...; António Borges Coelho, Inquisição de Évora. Dos Primórdios a 1668, 2 vols. (Lisboa 1987); Elvira Cunha de Azevedo MEA, A Inquisição de Coimbra. A Instituição, os Homens e a Sociedade (Porto 1997); Paulo Drumond Braga, A Inquisição nos Açores (Ponta Delgada 1997); Michèle Janin-Thivos TAILland, Inquisition et Société au Portugal. Le Cas du Tribunal d' Évora 1660-1821 (Paris 2001); Isabel M. R. Mendes Drumond BRAGA, Os Estrangeiros e a Inquisição Portuguesa (Séculos XVI-XVII) (Lisboa 2002) pp. 108-120, passim. 
terras de nascimento ou acolhimento para rumar a um país onde existia uma instituição como o Tribunal do Santo Ofício da Inquisição, cuja fama era conhecida por toda a Europa. Ou seja, quem arriscou? Porque o fez? E qual a representatividade de tal fenómeno?

Ao compulsarmos toda a documentação conhecida pela designação de «livros de reduzidos» no período de 1641 a 1700, dos tribunais de Lisboa, Évora e Coimbra ${ }^{11}$, verificamos que, entre os cerca de 1000 indivíduos que se reduziram, apareceram sete judeus e cristãos novos de origem peninsular. Isto é, estamos perante um processo residual e sem significado numérico, uma vez que representa menos de $1 \%$ do total dos indivíduos que empreenderam o referido processo de redução.

Em que consistia este procedimento? Reduzir-se significava deixar a fé inicial, neste caso o judaísmo, e aceitar como verdadeira a fé católica. Para isso realizava-se um processo de redução, constituido por um ou vários depoimentos da pessoa que se pretendia reduzir, a qual, em regra, ia acompanhada por um elemento do clero secular ou regular que a tinha instruído e conduzido à Mesa do Tribunal. Sob juramento ${ }^{12}$, o que se pretendia reduzir informava o inquisidor do seu nome, filiação, idade, estatuto sócioprofissional, naturalidade e motivos pelos quais tinha decidido reduzir-se. A par destes elementos, presentes na maioria dos casos, encontram-se ainda informações acerca dos motivos que tinham levado estas pessoas a deslocarem-se e a fixarem-se em Portugal, bem como há quanto tempo e em que local moravam. No caso de o indivíduo não falar português, havia um intérprete, frequentemente um religioso da mesma nacionalidade do que se pretendia reduzir. Quando estávamos perante menores de 25 anos, era nomeado um curador, normalmente o alcaide do cárcere, o porteiro da Mesa, ou outro qualquer funcionário do Santo Ofício. O indivíduo ainda costumava informar em que «seita» tinha sido

\footnotetext{
${ }^{11}$ Estes dados fazem parte de uma investigação que estamos a realizar de modo a estudarmos a natureza e a amplitude do fenómeno da redução em Portugal, durante o século XVII.

${ }^{12}$ De notar que, no caso do judeu Isac de Campos, o primeiro depoimento foi prestado depois de ter jurado sob o Talmud e o Segundo, igual ao primeiro, após o mesmo se ter baptizado, sobre as Sagradas Escrituras. Cf. Lisboa, A.N.T.T., Inquisição de Évora, liv. 562, fols 453-478.
} 
educado, passando posteriormente a afirmar ter sido doutrinado por certo religioso, ao mesmo tempo que declarava abjurar os erros que até então tinha professado e acreditar nos dogmas católicos e nos ensinamentos da Igreja em geral. $\mathrm{O}$ inquisidor recomendava prudência no contacto com hereges e mandava o indíviduo acabar a sua doutrinação com o religioso que o tinha instruido, devendo, posteriormente, apresentar uma declaração do mesmo atestando que tinha sido confessado e absolvido dos erros anteriores. Assim aconteceu com os cristãos-novos de judeus e com os judeus, tendo estes sido, entretan $\mathrm{O}$, baptizados ${ }^{13}$.

Entre 1662 e 1699, uma mulher e seis homens dirigiram-se aos tribunais de Lisboa e Évora relatando as suas vivências. Eram quatro judeus e três cristãos-novos. Na primeira situação estamos perante descendentes de sefarditas que nasceram durante a diáspora dos seus pais em Amsterdam, Hamburgo, Nice (ducado de Sabóia) e Pernambuco (Brasil), neste caso sob domínio holandês, ou seja entre 1630 e 1654 . Na segunda situação, temos crianças nascidas em Jaén, Sevilha e algures na Península Ibérica e, por isso mesmo, baptizadas; as quais acompanharam os seus pais para zonas de maior tolerância religiosa.

Saliente-se a juventude deste pequeno grupo, cujas idades estão compreendidas entre os 16 e os 27 anos: um com 16, dois com 18 e os restantes com 21, 23, 24 e 27 anos. Daí também não ser de estranhar que todos fossem solteiros, excepto a única mulher do grupo, que contava 18 anos. Apenas três homens se referiram às suas actividades. Um era mercador, o outro apresentou-se como sem ofício, vivendo de «sua agencia» e um terceiro era rabi, em Amsterdam, facto que não revelou de imediato.

Antes de chegarem a Portugal, estas pessoas estavam estabelecidas em diversas partes da Europa, acusando a diversidade de locais atingidos pelos que tinham empreendido a diáspora. Neste sentido, dois residiam em Amsterdam, dois em Livorno, um em

\footnotetext{
${ }^{13}$ Sobre reduzidos com base nas fontes inquisitoriais, cf., para Portugal, Paulo Drumond BRAGA, «Alemães na Lisboa Seicentista. As Conversões ao Catolicismo», em Akten der V. Deutsch-Portugiesischen Arbeitsgespräche / Actas do V Congresso Luso-Alemão (Köln - Lisboa 2000) pp. 421-433; para Espanha, Francisco Fajardo Spinola, Las Conversiones de Protestantes en Canarias. Siglos XVII y XVIII (Las Palmas de Gran Canaria 1996). Ambos os trabalhos referem-se a reduzidos de origem protestante.
} 
Esmirna, um em Hamburgo e um outro em Nice, independentemente de já terem realizado diversos percursos. Por exemplo, um viveu em Pernambuco antes de se fixar em Amsterdam, outros percorreram a França, a Turquia e o Egipto.

Os candidatos a reduzidos apareceram perante os inquisidores de livre vontade, afirmando desejarem receber o baptismo ou passarem efectivamente a viver como católicos, no caso dos que já possuiam aquele sacramento. Um foi acompanhado pelo capitão do pataxo que o trouxera ${ }^{14}$ e outro pelo dominicano frei Manuel Leitão que o tinha doutrinado ${ }^{15}$. Todos foram entregues a religiosos que os catequisaram, confessaram e absolveram para se concluir o processo de redução. Antes, contudo, evidenciaram as motivações, pelo menos aparentes, para os seus actos e relataram algumas das suas vivências judaicas, a par das vicissitudes das viagens rumo a Portugal.

Em 1662, o judeu Isac de Montesinos, natural de Pernambuco, de 23 anos, conseguiu escapar aos pais, residentes em Amsterdam. Segundo o seu depoimento, logrou cobrar umas patacas, durante uma ausência paterna, e embarcar-se. Antes da partida do navio esteve escondido «para não ser achado pelos judeos que o fizerão buscar com muito cuidado» ${ }^{16}$. Não tinha dinheiro suficiente para a viagem, mas apresentou-se ao capitão do navio, declarou o seu intento, e até se mostrou disponível para entregar a roupa que envergava. Ao chegar a Lisboa devia 60 florins, ou seja 24 patacas de oito reais ${ }^{17}$. Referiu ainda que tivera disputas com os irmãos e que os pais conheciam o seu interesse pelo cristianismo daí «lhe não consentião que tivesse dinheiro com [que] podesse por em execução os seus intentos» ${ }^{18}$.

Em 1682, temos a redução de Samuel Brazilis, judeu de Nice (Sabóia). Este jovem de 16 anos fugiu a remo atrás de um pataxo capitaneado por Roberto Loby, o qual contou aos inquisidores que, vindo do ducado de Sabóia, «meia legoa ao mar e com bastante vento que trazia ao pataxo em navegação seguida vio que

\footnotetext{
${ }^{14}$ Lisboa, A.N.T.T., Inquisição de Lisboa, liv. 713, fols 349-353.

${ }^{15}$ Lisboa, A.N.T.T., Inquisição de Lisboa, liv. 712, fols 1-9.

${ }^{16}$ Lisboa, A.N.T.T., Inquisição de Lisboa, liv. 711, fols 127-130.

${ }^{17}$ Lisboa, A.N.T.T., Inquisição de Lisboa, liv. 711, fols 127-130.

${ }^{18}$ Lisboa, A.N.T.T., Inquisição de Lisboa, liv. 711, fols 127-130.
} 
hum barco que sahira do mesmo porto o vinha seguindo e que vindo a remos e remava hua soo pessoa e o navio na forma referida sem amainar vella algua o barco e bradou o ditto pataxo que difficultozamente poderia abordar hua galle bem equipada e perguntando elle capitão ao remeiro do barco o que queria lhe disse que entregar-lhe a Samuel Brazilai hebreo de nação» ${ }^{19}$.

Anos mais tarde, em 1688, Isac de Campos, judeu nascido em Hamburgo, de 18 anos de idade, cujos pais - Jacob de Campos, mercador e Raquel da Serra - eram naturais de Coimbra; contou que os mesmos diziam «que se auzentarão deste reino com temor de serem prezos pello Santo Officio» e acrescentou que se embarcara em Hamburgo rumo a Ayamonte «por haver fugido a seus pais com animo de bautizar-se» ${ }^{20}$. Procurou realizar o seu intento na Andaluzia. Como lhe disseram que se tinha que dirigir à Inquisição de Sevilha, a qual ficava a 26 léguas de Ayamonte, foi aconselhado por Portugueses a deslocar-se a Faro que distava apenas nove léguas. Naquela cidade, esteve em casa do bispo D. Simão da Gama, durante 15 dias, seguindo depois para Évora, a sede do tribunal mais próxima ${ }^{21}$.

Mais aparatosa parece ter sido a viagem de Jacob Rodrigues ou Jacob Reis da Costa, rabi de Amsterdam, que talvez tenha vindo para reavivar a fé da comunidade cristã-nova portuguesa, mas que acabou por se reduzir, eventualmente para não cair nas malhas do Santo Ofício. Este homem começou por afirmar ter naufragado no estreito de Gibraltar, quando vinha a bordo de um navio mercantil que se perdera. Morreram 48 pessoas e salvaram-se 72 . No seu caso, o recurso a uma bóia improvisada foi responsável por não se ter afogado, já que conseguiu meter-se «em hua pipa que sahio no porto de Gibraltar». Aí tomou um barco português que o terá conduzido ao Algarve. Percorreu diversas terras do Alentejo, dirigindo-se ao hospital de Beja, onde procurou um seu irmão, Jácome Moisés, que há seis anos ali tinha ficado internado, em resultado de ter sofrido um naufrágio durante a guerra da liga de Augsburgo ou do Palatinado (1688-1697), atendendo às datas ${ }^{22}$. Segundo

${ }^{19}$ Lisboa, A.N.T.T., Inquisição de Lisboa, liv. 713, fols 349-353.

${ }^{20}$ Lisboa, A.N.T.T., Inquisição de Évora, liv. 562, fols 453-478.

${ }^{21}$ Lisboa, A.N.T.T., Inquisição de Évora, liv. 562, fols 453-478.

${ }^{22}$ Trata-se de uma guerra, dirigida pela Inglaterra, que opôs quase toda a Europa à França. Visava travar o expansionismo de Luís XIV, que acabou derrotado. 
Jacob, a sua intenção era «se recolherem ambos pera sua terra». No hospital tomou conhecimento da morte do irmão e, sem apresentar qualquer razão, disse ter decidido reduzir-se. Foi então encaminhado para casa de um comissário do Santo Ofício ${ }^{23}$.

Entre os motivos que foram aduzidos para a passagem à prática do cristianismo ressaltam os contactos com os católicos - laicos ou religiosos - algures na Europa. A procura de familiares e as leituras de textos sagrados também foram evidenciadas. Num único caso, a redução aparece como uma eventual forma de escapar a severas punições do Santo Ofício, já que não é plausível que um rabi recém chegado a Portugal (situação que o próprio começou por ocultar) desejasse tornar-se católico sem qualquer fortíssimo motivo. Parece, pois, poder colocar-se a hipótese de estarmos perante uma tentativa de escapar a um castigo significativo, nomeadamente o relaxamento ao braço secular, por parte de um indivíduo que se dedicaria ao proselitismo judaico e que, ao ser objecto de suspeita, tenha optado pela única via que lhe evitaria problemas até sair do reino ${ }^{24}$.

Isac de Montesinos declarou que «nasceo na judaysmo e nelle foi criado e instruido por seus pays e sendo de idade de oito dias foi circuncidado e despois que se começou a entender observou sempre as cerimonias da ley de Moyses e despois que os olandeses forão lançados de Pernambuco o levarão seus pays para Olanda e de dous annos a esta parte por meio da lição da sagrada escritura e de hua Biblia de um religioso da ordem de São Francisco que havia em casa de seu pay entendeo que hia errado para a salvação de sua alma em crer na ley de Moyses e viver no judaismo» ${ }^{25}$.

Diferente foi a motivação da cristã-nova Isabel ou Rosa Mendes Malin, de 18 anos, natural da Península Ibérica e moradora em Livorno, para onde fora com 13 meses de idade. Esta jovem, educada pelos tios, professou publicamente o judaísmo, confessou a prática de todas as cerimónias judaicas e viajou com o marido em busca do Messias: «forão a Alexandria, Ismirna e ao Grão Cairo com ocazião da nova que houve de que era vindo o Messias

\footnotetext{
${ }^{23}$ Lisboa, A.N.T.T., Inquisição de Évora, liv. 562, fols 537-550v.

${ }^{24}$ Tal é o caso de Jacob Rodrigues ou Jacob Reis da Costa. Cf. Lisboa, A.N.T.T., Inquisição de Évora, liv. 562, fols 537-550v.

${ }^{25}$ Lisboa, A.N.T.T., Inquisição de Lisboa, liv. 711, fols 127-130.
} 
e em todas estas partes se tratarão sempre por judeos» ${ }^{26}$. Viajou também em França e, em Bordéus, encontrou um antigo criado do pai, o qual lhe disse que aquele vivia em Portugal. Essa terá sido a motivação para esta mulher se dirigir a terras lusas, onde efectivamente encontrou o seu progenitor que a motivou à redução, informando-a que ela e o marido «não hião bem encaminhados porque a ley de Moyses era ja extinta e que so na ley de Christo Senhor nosso havia salvação» ${ }^{27}$.

Evidenciando já o contacto com elementos do clero, traduzidos de forma inequívoca no tipo de discurso, o cristão-novo João Nunes, de 24 anos, natural de Jaén, morador em Esmirna e então fixado em Lisboa, na rua das Mudas, afirmou que há três anos, alumiado pelo Espírito Santo ${ }^{28}$, fugira à sua mãe e dirigira-se a Marselha, daí a Castela e posteriormente a Portugal. Só tinha tido conhecimento do cristianismo pouco antes de partir, já que, com dois anos, fora levado pelos pais de Jaén para Esmirna e aí aprendera a lei de Moisés na escola de Isac, que frequentara até aos 15 anos ${ }^{29}$.

Diogo Fernandes Silva, cristão-novo, de 21 anos, mercador, natural de Sevilha e morador em Lisboa, em 1675, referiu que havia um ano, que o contacto com um sacerdote em Livorno lhe alterara a vida. Tendo tomado conhecimento com o padre mestre José dos Anjos, religioso de São João Evangelista, que vinha de Roma com destino a Portugal «praticou com elle sobre a ley catholica romana e lhe declarou que tinha grande vontade de se reduzir a ella e sahir-se daquella cidade e companhia de seus pays» ${ }^{30}$.

Para Samuel Brasilis as motivações para a fuga foram explicadas aos inquisidores, evidenciando mais uma vez o contacto com católicos, desta feita laicos: «ter visto aos moços do seu tempo que erão catholicos e seus condiscipulos na escola seguirem a ley de Christo Senhor Nosso entendeo que era a unica e verdadeira para a salvação das almas» ${ }^{31}$, daí dirigir-se a Portugal para se baptizar e seguir o catolicismo.

\footnotetext{
${ }^{26}$ Lisboa, A.N.T.T., Inquisição de Lisboa, liv. 711, fols 63-67.

${ }^{27}$ Lisboa, A.N.T.T., Inquisição de Lisboa, liv. 711, fols 63-67.

${ }^{28}$ Este é um argumento frequentemente utilizado pelos que se reduziam e que torna evidente alguma doutrinação por parte do clero. Cf. Paulo Drumond BRAGA, «Alemães na Lisboa Seiscentista ...», pp. 421-433.

${ }^{29}$ Lisboa, A.N.T.T., Inquisição de Lisboa, liv. 712, fols 1-9.

${ }^{30}$ Lisboa, A.N.T.T., Inquisição de Lisboa, liv. 712, fols 258-262.

${ }^{31}$ Lisboa, A.N.T.T., Inquisição de Lisboa, liv. 713, fols 349-353.
} 
Contacto com católicos também foi salientado por Isac de Campos, que declarara desejar tornar-se católico há ano e meio. Desta feita, tornou-se claro o aliciamento de um laico, quando o jovem tinha cerca de 16 anos: «costumava elle declarante ir a caza do ditto espanhol e este lhe dava confizes e doces e depois de ter com elle mais confiança lhe disse que quando moresse havia ir direito ao inferno porque vivia na cegueira da ley de Moyses cuja ley ja não era boa e estavão esperando pello Messias que ja tinha vindo» ${ }^{32}$. O seu intento, de receber o baptismo, foi conseguido, a 5 de Setembro de 1688, através do Doutor Manuel de Oliveira Pinto, provisor do arcebispado, na sé de Évora.

Este grupo de judeus e cristãos-novos não deixou de referir diversas práticas judaicas, desde a procura do Messias à circuncisão, passando por festas como a Páscoa das Cabanas. A frequência das sinagogas, a guarda dos sábados e o consumo de pão ázimo também não foram esquecidos.

Se Isabel viajou com o marido em busca do Messias ${ }^{33}$, Isac de Campos contou que fora circuncidado pelo rabi da sinagoga de Hamburgo ${ }^{34}$, enquanto Jacob Rodrigues ou Jacob Reis da Costa especificou as várias maneiras de se proceder à circuncisão: «vem a casa do pay do menino que aonde sircunsidar hum dos rabinos da sinagoga se querem da pessoa que esta deputada para ser padrinho tem o menino nas mãos e esta assentada em hua cadeira e sobre os joelhos tem hua almofada sobre a qual poem o menino que haonde sircunsidar [ou] pondo uma cadeira e assentando nella o pay do menino a qual esta sobre hua meza do rabino com hua tanas de prata pega na pelle do perpuçio e com hum canivete corta a pelle do mesmo perpuçio e deita-lhe huns pos com que estanca logo o sangue e as gotas que caem as toma em hua toalha» ${ }^{35}$. $\mathrm{Na}$ noite da véspera da circuncisão, consoante as possibilidades das famílias, era dada uma festa ou servido um banquete.

Por seu lado, João Nunes salientou o seu quotidiano enquanto judeu: «todas as manhas hia ás sinagogas em companhia dos mais que também andavão na escola que todos erão judeus sem serem

${ }^{32}$ Lisboa, A.N.T.T., Inquisição de Évora, liv. 562, fols 453-478.

${ }^{33}$ Lisboa, A.N.T.T., Inquisiçâo de Lisboa, liv. 711, fols 63-67.

${ }^{34}$ Lisboa, A.N.T.T., Inquisição de Évora, liv. 562, fols 453-478.

${ }^{35}$ Lisboa, A.N.T.T., Inquisição de Évora, liv. 562, fols 537-550v. 
bautizados e o ditto seu mestre e nella dizião as orações que se costumão dizer que são sessenta em numero e que os dittos seus pais tambem hião ás sinagogas e guardavão a ley de Moises e fazião suas cerimonias como era a guarda dos sabbados, paschoas das cabanas e pão asmo e outras e elle confitente fazia o mesmo» ${ }^{36}$.

Diogo Fernandes Silva contou que era filho dos cristãos-novos Diogo Fernandes Silva ou David Fernandes e Raquel Fernandes, com os aqueles tinha ido para Livorno, quando contava apenas um ano. Aí passaram todos a praticar abertamente o judaísmo, religião na qual os pais se mantinham. Ele fora circuncidado e frequentava as sinagogas na companhia dos progenitores: «indo com os dittos seus pays as sinagogas e rezando as orações da ditta ley que estão em hum livro sendo que nunca foi muito observante dellas pela qual rezão tinha alguns disgostos com seus pays» ${ }^{37}$.

Aos inquisidores interessava saber o que faziam os cristãosnovos depois de sairem de Portugal. Assim, não deixavam escapar a opcrtunidade de obterem notícias sobre determinadas pessoas e situações. Aceitavam-se denúncias ou informações sobre práticas judaizantes ou outras ${ }^{38}$, ao mesmo tempo que se procuravam obter de qualquer fonte, incluindo os candidatos a reduzidos, algumas notícias que permitissem descobrir ou incriminar os que tinham saído e que, eventualmente, poderiam regressar.

João Nunes referiu três castelhanos que frequentavam a sinagoga de Esmirna: Isac Calvo, Isac Sereno e Jacob Dias, todos casados ${ }^{39}$. Diogo Fernandes Silva interrogado sobre a presença de cristãos-novos que praticavam o judaísmo, em Livorno, respondeu «não se alguns dos judeos que continuão pubricos profitentes da ley de Moyses nas sinagogas são baptisados ou não nem outosi tem noticias de seus nomes mas que os que tem por judeus porem que os mais delles fallão portugues e castelhano» ${ }^{40}$. Por seu lado, Isac de Campos referiu-se também a Moisés Coriel, seu primo, também conhecido por Jerónimo Nunes da Costa, nome que utilizava quando «se cartea com Portugal». Este homem era corres-

${ }^{36}$ Lisboa, A.N.T.T., Inquisição de Lisboa, liv. 712, fols 1-9.

${ }^{37}$ Lisboa, A.N.T.T., Inquisição de Lisboa, liv. 712, fols 258-262.

${ }^{38}$ Isabel M. R. Mendes Drumond BragA, Os Estrangeiros e a Inquisição ..., pp. 108-120, passim.

${ }^{39}$ Lisboa, A.N.T.T., Inquisição de Lisboa, liv. 712, fols 1-9.

${ }^{40}$ Lisboa, A.N.T.T., Inquisição de Lisboa, liv. 712, fols 258-262. 
pondente do rei D. Pedro II, em Hamburgo, onde, de entre outras actividades, mandava fazer navios. Segundo o mesmo depoimento, Jerónimo Nunes da Costa chegou a usar luto pela morte da rainha de Portugal, D. Maria Francisca Isabel de Sabóia (falecida em 1683), nas suas palavras «trouxe do por ella» ${ }^{41}$. Estas informações, de 1688, interessaram de tal modo os inquisidores que, em 1699, ao contactarem com Jacob Rodrigues ou Jacob Reis da Costa, judeu de Amsterdam, não se esquecerem de perguntar se conhecia o referido Jerónimo Nunes da Costa ou Moisés Coriel, ao que o reduzido respondeu afirmativamente, acrescentando que o mesmo falecera havia cerca de dois anos ${ }^{42}$.

Apresentadas as razões aparentes para empreender esta diáspora ao contrário fica a dúvida: qual ou quais as verdadeiras intenções destas pessoas ao reduzirem-se à fé católica? Se é um facto que, no caso do antigo rabi, podemos estar perante uma saída desesperada para evitar o pior, já nos restantes não parece haver motivações profundas. Será a vontade de encontrar parentes suficientemente forte para explicar a vinda mas já não tão forte para explicar a redução a não ser, mais uma vez, como uma forma de evitar suspeitas e problemas para quem sempre tinha vivido praticando o judaismo. No caso dos que, aparentemente, foram motivados por católicos, algures na Europa, atendendo a que não tinham necessidade de viver em Portugal, e atendendo também à juventude dos mesmos, poderemos interrogar-nos se estamos perante pessoas que não deixam de evidenciar uma certa rebeldia típica de certa faixa etária, ou de pessoas com uma deficiente doutinação judaica que se deixaram seduzir por uma religião descrita como a única verdadeira.

${ }^{41}$ Lisboa, A.N.T.T., Inquisição de Évora, liv. 562, fols 453-478.

${ }^{42}$ Lisboa, A.N.T.T., Inquisiçãao de Évora, liv. 562, fols 537-550v. 
Reduzidos de Origem Judaica (1641-1700)

\begin{tabular}{|l|c|l|l|l|l|l|c|l|}
\hline Nome & Idade & Estado & Situação & Actividade & Natural & Morador & Data & Fonte \\
\hline Isac Montesinos & 23 & Solteiro & Judeu & - & Pernambuco & Amsterdam & 1662 & $\begin{array}{l}\text { Inquisição de Lisboa, liv. 711, fols } \\
127-130\end{array}$ \\
\hline $\begin{array}{l}\text { Isabel ou Rosa } \\
\text { Mendes Malin }\end{array}$ & 18 & Casada & $\begin{array}{l}\text { Cristã- } \\
\text { Nova }\end{array}$ & - & $\begin{array}{l}\text { Península } \\
\text { Ibérica }\end{array}$ & Livorno & 1669 & $\begin{array}{l}\text { Inquisição de Lisboa, liv. 711, fols } \\
63-67\end{array}$ \\
\hline João Nunes & 24 & Solteiro & $\begin{array}{l}\text { Cristão- } \\
\text { Novo }\end{array}$ & $\begin{array}{l}\text { «Vive de sua } \\
\text { agencia» }\end{array}$ & Jaén & Esmirna & 1673 & $\begin{array}{l}\text { Inquisição de Lisboa, liv. 712, fols } \\
1-9\end{array}$ \\
\hline $\begin{array}{l}\text { Diogo Fernandes } \\
\text { Silva }\end{array}$ & 21 & Solteiro & $\begin{array}{l}\text { Cristão- } \\
\text { Novo }\end{array}$ & Mercador & Sevilha & Livorno & 1675 & $\begin{array}{l}\text { Inquisição de Lisboa, liv. 712, fols } \\
258-262\end{array}$ \\
\hline Samuel Brasilis & 16 & Solteiro & Judeu & - & Nice & Nice & 1682 & $\begin{array}{l}\text { Inquisição de Lisboa, liv. 713, fols } \\
349-353\end{array}$ \\
\hline Isac de Campos & 18 & Solteiro & Judeu & - & Hamburgo & Hamburgo & 1688 & $\begin{array}{l}\text { Inquisição de Évora, liv. 562, fols } \\
453-478\end{array}$ \\
\hline Jacob Rodrigues & 27 & Solteiro & Judeu & Rabi & Amsterdam & Amsterdam & 1699 & $\begin{array}{l}\text { Inquisição de Évora, liv. 562, fols } \\
537-550 v\end{array}$ \\
\hline
\end{tabular}




\section{RESUMEN}

Este artículo aborda el tema de algunos judíos y cristianos nuevos descendientes de judíos peninsulares que, en el siglo XVII, llegaron a Portugal y se convirtieron al catolicismo.

Las fuentes para este estudio son los libros de convertidos del Santo Oficio de la Inquisición. Éstos nos proporcionan datos acerca de las personas (edad, estado civil, lugar de nacimiento y de residencia) y, especialmente, sobre la vivencia del judaísmo en diferentes partes de Europa, así como sobre las motivaciones, reales o aparentes, para la conversión.

PalabRas Clave: Conversión al catolicismo, diáspora, Inquisición, Portugal.

\section{SUMMARY}

The present paper deals with a number of Jewish and new Christian people, descendants of Peninsular Jews, who arrived in Portugal in the $16^{\text {th }}$ century and consequently converted to Catholicism.

The source material used in this study are the Books of Converted Jews that belonged to the Holy Office of Inquisition. These books provide information on the nature of the people (age, status, birthplace, place of residence), the way they experienced their religion in different parts of Europe, and the true or apparently true reasons for their conversion.

KEYwORDS: Conversion to Catholicism, Diaspora, Inquisition, Portugal. 